\title{
Technical aspects of the cesarean section
}

\author{
Daniele Bolla • Andrea Schöning • Gero Drack • \\ René Hornung
}

Received: 28 November 2009 / Accepted: 13 January 2010/Published online: 13 February 2010

(C) Springer-Verlag 2010

\begin{abstract}
The aim of this study was to evaluate every part of the surgical procedure during cesarean section (CS) to prevent complications and improve the clinical outcome. We researched on PubMed, Medline, and Cochrane. The evidence-based research suggests a transverse incision of the skin, blunt dissection of the subcutaneous tissue, omission of the bladder flap, blunt extension of the hysterotomy, prophylactic antibiotics, spontaneous placental removal, leaving the peritoneum open, and suture closure of the subcutaneous tissue when thickness is $\geq 2 \mathrm{~cm}$. We hope that all evidence-based description will help to perform the CS safer, and for all surgical procedures not yet studied, further research is needed.
\end{abstract}

Keywords Cesarean section · Pfannenstiel incision . Joel-Cohen incision · Uterine incision

\section{Introduction}

The cesarean section (CS) has evolved over a millennium and is considered the oldest major obstetric operation. The World Health Organization (WHO) recommends that the rate of cesarean sections should not exceed $15 \%$ in any country. But in reality, it continues to increase, varying considerably between countries and health services. In Switzerland, there is a rate of $29.2 \%$ [24]; but, in other countries like Chile, it increased up to $40 \%$ [37], and also, in the USA, the rate rose from $20 \%$ to $31.1 \%$ [42] during the last decade.

D. Bolla $(\bowtie) \cdot$ A. Schöning $\cdot$ G. Drack $\cdot$ R. Hornung

Department of Obstetrics and Gynecology,

Kantonspital St. Gallen, St. Gallen, Switzerland

e-mail: daniele.bolla@kssg.ch
As in most surgical procedures, there is no standard technique, and for this reason, there are many possible ways to perform a cesarean section. The CS is associated with a low maternal mortality rate. It has became a safe procedure in the last 50 years because of the improvement of surgical and anesthesiological techniques as well as the routinely use of antibiotics.

The aim of this article is to research techniques of CS and to provide an evidence-based guidance to facilitate surgical decision making. The purpose was to evaluate every surgical procedure to prevent possible complications and at the same time to optimize clinical outcome.

\section{Material and methods}

We searched literature published in MEDLINE, PubMed, or Cochrane between 1971 and 2009. The terms searched for were cesarean section, cesarean delivery, and cesarean pregnancy, and we were focusing on randomized trials, analyzing technical aspects. All randomized trials that covered surgical and selected nonsurgical aspects of CS where included in the review. Each manuscript or review was carefully evaluated and any pertinent references from the manuscripts where obtained and reviewed.

\section{Results}

Lateral tilt Lateral tilt is a consolidated obstetric practice to reduce the aortocaval compression by the gravid uterus. This reduction is reached with a lateral tilt of $12.5^{\circ}-15^{\circ}$ [29]. This intraoperative position can also cause compression of the underlying structures defined as a sciatic neuropathy, and for this reason, it is important to reduce 
the time in this position as much as possible. Unfortunately, the trials analyzed were all methodologically poor; but when lateral tilt was used, the Apgar scores of the newborn, the $\mathrm{pH}$ measurements, and oxygen saturation appeared to be better than in the supine position $[25,50]$.

Skin cleaning The purpose of the skin cleaning is to reduce the bacterial colonization. Usually the skin preparation is performed with a preoperative shower, then a scrub with bactericidal soap in the operating room, followed by application of a long-acting bactericidal agent. A systematic review has shown that no reduction in surgical site infection was found for preoperative bathing with chlorhexidine soap compared with bar soap or placebo [46]. Some surgeons apply only the long-acting bactericidal agent without the preoperative applications of soap and seem to be equal effective compared with the traditional method. The rate of wound infection is not dependent on the antiseptic solution chosen $[18,25]$. Therefore, the use of an iodine solution alone is considered reasonable. It is also proven that the use of prophylactic antibiotics reduces the risk of infections (endometritis or wound infections) independently of the way of skin cleaning [32].

Adhesive drapes Adhesive drapes do not reduce surgical site infection. This was evaluated in a systemic review of randomized trials which demonstrated no benefit. Also, the iodine-impregnated adhesive drape versus no adhesive drape had no effect on the surgical site infection rate (RR, 1.03; 95\% CI 0.064-1.66) [25, 48].

Skin incision In general, a transverse incision is most commonly used for cesarean delivery since it is associated with less postoperative pain, greater wound strength, and better cosmetic results than the midline incision [6]. Midline incisions compared with transverse incisions have more wound dehiscence/infection (eight times more; $2.94 \%$ VS $0-0.37 \%$ ) [36] and undoubtedly also increase the incidence of incision hernia $[30,45]$. However, midline incisions generally are believed to allow faster abdominal entry because of less bleeding and nerve injury and can be easily extended in cranial direction if more space is required [22]. The preferred transverse incisions worldwide are the Pfannenstiel and the Joel-Cohen (JC) incisions. The Pfannenstiel incision is slightly curved, 2 to $3 \mathrm{~cm}$ or two fingers above the symphysis pubis, with the mid-portion of the incision within the shaved area of the pubic hair. The JC incision, on the contrary, is straight, $3 \mathrm{~cm}$ below the line that joins the anterior superior iliac spines and therefore more cranial than the Pfannenstiel incision. A modified JC incision which is named the Stark cesarean section has proved to have advantages compared with the traditional Pfannenstiel incision because of a shorter surgical time, fewer sutures, lower febrile morbidity, and fewer postoperative hematomas above and under the fascia $[5,15,34]$. In 1999, Wallin presented also a modified Joel-Cohen technique for cesarean delivery (incision $3 \mathrm{~cm}$ above the symphysis pubis, closure of uterine incision with a single layer and no peritoneal closure). This method has been proven to be much faster, then the Pfannenstiel technique especially in delivering the fetus $[25,34,47]$, but this is not clinically relevant because of equal neonatal outcome $[15,19]$. However, considering the less cosmetic appearance of the JC abdominal wound, it should be limited only to the emergency cesarean section.

Subcutaneous incision/opening The safety and efficacy of electrocautery compared with the cold scalpel for midline abdominal incision was analyzed in a multicenter collaborative study. On animal trials, the use of electrocautery had shown an increment of wound infection. These findings were not confirmed in this clinical trial that involved 964 patient, and the results reported no differences in wound infections between the electrocautery and the cold scalpel [20]. It is proven that an electrocautery can induce pacemaker failure [4]. For this reason, some authors believe that a unipolar electrocautery can also cause a fetal injury during the surgery. However, this hypothesis has not been proven so far by any study. Blunt dissection (with fingers) has been associated with a shorter operating time and, in addition, most operators use the scalpel as less as possible, opening layers bluntly (from medial to lateral) to avoid injury to the tissue and the inferior epigastric vessels [6].

Fascial incision There are no randomized trials comparing different techniques of opening the fascia at CS. Most experts recommend a transverse incision that is performed with the scalpel and then extended with scissors. Alternatively, the fascial incision can be extended laterally with the fingers (Misgav-Ladach techniques) [6].

Rectus muscle The rectus muscle can be separated bluntly or by scissors. Various studies have shown that cutting transversely the rectus muscle versus not cutting was not associated with any difference in operative morbidity, difficult deliveries, increase of postoperative complications, or higher pain scores. For this reason, transecting the rectus muscle seems to be unnecessary and does not preserve the muscle's strength $[7,21]$.

Opening of the peritoneum Opening of the peritoneum has not been studied separately in a randomized trial. Many authors recommend opening the peritoneum carefully using the fingers to minimize the risk of injury to other organs adherent to the underlying surface. For this reason, a sharp entry is considered unnecessary $[47,52]$. 
Bladder flap Bladder flap was studied in a single trial involving 102 women delivering by cesarean section. The omission of the bladder flap (direct incision $1 \mathrm{~cm}$ above the bladder fold) was associated with a reduction in operating time ( 5 vs. $7 \mathrm{~min}$; $P=0.001$ ), blood loss [postoperative microhematuria $(21 \%$ vs. $47 \% ; P=0.01)$ and need for analgetics ( $26 \%$ vs. $55 \% ; P=.006 ; 26]$. The rate of a bladder adherent to the uterus at repeated cesarean section was demonstrated to be higher in those who had a bladder flap performed in a previous CS [38]. The bladder flap is justified only if a difficult delivery is anticipated like a vertex presentation deep in the pelvis. Unfortunately, the long-term consequences of this procedure were not evaluated [26].

Uterine incision Uterine incision can be performed in many different ways. The way of incision depends on many factors including the position of the fetus, the location of the placenta, and development of the lower uterine segment. The most common procedure is the transverse incision of lower uterine segment (called Kerr incision or Monroe-Kerr) also because, compared with the vertical incision, this incision means less blood loss, less need of bladder dissection, and a lower risk of rupture in following pregnancies [31, 40]. If necessary, a transverse incision can be expanded laterally (like a "J" or a "U") or vertically (like a reverse "T"). These different incisions have substantially the same rate of complication during the operation and the same postoperative morbidity, but the intraoperative risk is higher (blood loss, change in the mean hematocrit/hemoglobin, unintended extension of incision into the broad ligament, laceration of the cervix) when a transverse incision is performed [31]. The type of incision (vertical or transverse) in subsequent pregnancies is associated with a different risk of uterine rupture. The risk of rupture in a vertical incision is $2.2 \%$ compared with a transverse incision (in the lower uterine segment) that decreases to $0.038-0.5 \%$ [10]. In general, a woman with only one foregone CS (incision in the lower uterine segment) has a risk of uterine rupture of $0.8 \%$ compare to two or more CS where the risk grows to $3.7 \%(\mathrm{OR}=4.8,95 \% \mathrm{CI}, 1.8-13.2$; $P=0.001$ ) [10].

Expansion of uterine incision The hysterotomy incision can be extended either bluntly or by scissors. These two techniques were studied in two randomized trials, which showed different results. One reported an association between sharp dissection and increased blood loss (886 vs. $843 \mathrm{~mL} ; P=0.001)$, but the other reported the two techniques as equivalent (postpartum hemoglobin levels 9.9 vs. $10.3 \mathrm{~g} / \mathrm{dL} ; P=.12)[31,41]$. Because of the risk to injure the neonate or the cord and also because it is faster, blunt expansion should be preferred to sharp expansion of uterine incision. A recent study compared also a blunt expansion (with the fingers) in a transversal vs. in a cephalic-caudal direction of the uterine incision. The outcome seems to prove a higher incidence of unintended extension $(7.4 \%$ vs. $3.7 \% ; P=.03)$ and blood loss $>1,500 \mathrm{~mL}(2.0 \%$ vs. $0.2 \%$; $P=.04)$ when the transverse expansion is performed [14]. Some studies have evaluated the use of the stapling technique to reduce the blood loss. This procedure was associated with a longer time to deliver the baby, compared with the traditional method, and no benefits were found in maternal or fetal outcomes [49].

Instrumental delivery The instrumental delivery has been suggested to assist the fetal head at cesarean section when the delivery is found to be difficult and atraumatic manual delivery is not possible. Actually, there are not enough data to express a proposal about the instrumental delivery. In the absence of clear evidence of benefit, a routine use of vacuum extraction or forceps at the time of cesarean delivery is not justified, given its potential for serious fetal injury (extra- and intracranial hemorrhage) [12]. The most common technique is to insert the hand into the uterine cavity to flex the fetal head and bring it to the level of the uterine incision, from which it can be extracted [8].

Prophylactic antibiotics The use of prophylactic antibiotics in women undergoing cesarean section were studied in more than 80 randomized trials. All these studies show benefit in both elective (none laboring) and non-elective (laboring) CS. The decrease in incidence of endometritis was $>60 \%$ in both, elective (RR, 0.38; 95\% CI, 0.22-0.64) and non-elective (RR, 0.39; 95\% C, 0.34-0.46), with $>2,000$ women who were randomly assigned in each analysis [43]. The decrease in wound infection was approximately $25 \%$ in elective CS and $65 \%$ in nonelective CS. In other 51 randomized trials, the incidence of endometritis was equivalent in using ampicillin or firstgeneration cephalosporins. A multiple dose regimen for prophylaxis or a broader spectrum agent in a single dose does not appear to offer additional benefit [25, 27].

Placental removal Randomized trials have shown that a gentle traction on the cord and the use of oxytocin reduce postoperative endometritis (OR 0.62. 95\% CI 0.48-0.80) and blood loss compared with manual traction. In this way, it is also not needed to change the gloves after removing the placenta $[6,35,51]$.

Uterine exteriorization Nine randomized studies evaluated the position of the uterus at the time of repair. The metaanalysis suggests that there is no significant difference in outcome leaving the uterus intra-abdominally or exteriorization for uterine incision repair (except for the shorter operating time and less nausea) [13, 39]. 
Cervical dilatation The intraoperative cervical dilatation during cesarean section was studied in one randomized controlled study. No differences were found in maternal fever, wound infection, or change in hemoglobin concentration between this group and the other not undergoing the intraoperative cervical dilatation [1].

Closure of uterine incision Closure of uterine incision is actually still discussed. In literature, there are many different ways of closing the uterine incision. To avoid bleeding from the incision edges, a continuous closure incorporating all the muscle without including the endometrium is preferred. It is faster, and no increased risk of uterine rupture, hemorrhage, and infection was found [15]. Diverse studies have analyzed single- versus double-layer closure. According to the review of the Cochrane Library, blood loss and the need for transfusion, as well as endometritis rates were not different in this two techniques $[9,16]$. Single-layer closure shortens the operating time. However, it seems to increase the risk of uterine rupture during following pregnancies. Other studies did not confirm this risk, but showed a higher frequency of asymptomatic uterine dehiscence. According to this, there is not enough evidence for the routine use of a single-layer closure compared with double-layer closure [17]. Further investigations are needed to analyze which factors can affect the strength of the closure.

Intra-abdominal irrigation Intra-abdominal irrigation with the use of prophylactic antibiotics seems not to reduce the maternal morbidity [23]. The same is also valid for the irrigation of the subcutaneous tissue.

Peritoneal closure versus non-closure Peritoneal closure versus non-closure was evaluated in many randomized trials and summarized in a Cochrane Review [16]. It is in generally evident that non-closure of the peritoneum (visceral and parietal) reduces the operating time, the postoperative fever (wound infections), and the postoperative hospital stay. Also the analgetic requirements favor a non-closure. The longterm follow-up showed no differences in pain, fertility, urinary symptoms, and adhesions [38, 44, 45]. It is proven that closure of the visceral peritoneum at cesarean delivery may produce an inflammatory reaction and adhesions, caused by reactive and regenerative mesothelial hyperplasia and submesothelial fibrosis [33].

Reapproximation of rectus muscle Reapproximation of rectus muscle seems to be unnecessary also because the muscles tend to find the right anatomic location by itself. For this reason and because it may produce unnecessary pain when the woman starts to move after the operation, suturing it is not recommended $[6,45]$. There are no published data to support or refuse these claims. Further studies are needed.
The technique of fascia closure The technique of fascia closure has not been studied in any trial. Many clinicians agree to close the fascia with a delayed absorbable, running, and nonlocking suture [6].

Subcutaneous tissue closure versus non-closure Subcutaneous tissue closure is recommended in women with a depth of more than $2 \mathrm{~cm} \mathrm{[3].} \mathrm{Closure} \mathrm{of} \mathrm{dead} \mathrm{space} \mathrm{seems} \mathrm{to} \mathrm{inhibit}$ accumulation of serum and blood that can lead to a dehiscence of the wound [11]. The general clinical experience is to close these subcutaneous tissues with a delayed absorbable, interrupted, nonlocking suture.

Closure of skin There are not enough data to give a recommendation how to reapproximate the skin. Usually, this closure is performed with staples or suture $[2,25]$.

\section{Comment}

The cesarean section in obstetrics is one of the most common and oldest surgeries. But still, for some surgical procedures, there are not enough data to give an evidence-based recommendation. In our profession, it is very important to improve our technique based on well-performed studies.

The evidence-based surgical steps described to perform a cesarean section are recommended for all the pregnant undergoing the first CS. This is because the anatomy in women with one or more CS can be very different, and for this reason, some passages in performing this operation have an increased risk of complication (malpresentation, placenta previa, antepartum hemorrhage, placenta accreta, prolonged labor, uterine rupture, preterm birth, low birth weight, and stillbirth) [28]. However, some authors define that some risks may be due to confounding factors related to the indication for the first cesarean section, rather than due to the procedure itself.

We hope that all the evidence-based technical aspects described above will help to perform the CS in a safer way. However, further research is needed to clarify persisting controversies in the technique of cesarean section.

Conflict of interest There is no actual or potential conflict of interest in relation to this article.

\section{References}

1. Ahmed B, Abu Nahia F, Abushama M (2005) Routine cervical dilatation during elective cesarean section and its influence on maternal morbidity: a randomized controlled study. J Perinat Med 33(6):510-3

2. Alderdice F, McKenna D, Dornan J. Techniques and materials for skin closure in caesarean section. Cochrane Database Syst Rev. 2003;(2):CD003577. Review 
3. Anderson ER, Gates S. Techniques and materials for closure of the abdominal wall in caesarean section. Cochrane Database Syst Rev. 2004 Oct 18;(4):CD004663. Review.

4. Bales JG, Colon J, Ramadhyani U, LeDoux E, Bennett JT (2007) Electrocautery-induced asystole in a scoliosis patient with a pacemaker. J Pediatr Orthop B 16(1):19-22

5. Belci D, Kos M, Zoricić D, Kuharić L, Slivar A, Begić-Razem E et al (2007) Comparative study of the "Misgav Ladach" and traditional Pfannenstiel surgical techniques for cesarean section. Minerva Ginecol 59:231-240

6. Berghella V, Baxter JK, Chauhan SP (2005) Evidence-based surgery for cesarean delivery. Am J Obstet Gynecol 193:1607

7. Berthet J, Peresse JF, Rosier P, Racinet C (1989) Comparative study of Pfannenstiel's incisions and transverse abdominal incision in gynecologic and obstetric surgery. Presse Med 18: 1431-1433

8. Bofill JA, Lencki SG, Barhan S, Ezenagu LC (2000) Instrumental delivery of the fetal head at the time of elective repeat cesarean: a randomized pilot study. Am J Perinatol 17(5):265-269

9. Bujold E, Bujold C, Hamilton EF, Harel F, Gauthier RJ (2002) The impact of a single-layer or double-layer closure on uterine rupture. Am J Obstet Gynecol 186(6):1326-1330

10. Caughey AB, Shipp TD, Repke JT, Zelop CM, Cohen A, Lieberman E (1999) Rate of uterine rupture during a trial of labor in women with one or two prior cesarean deliveries. Am J Obstet Gynecol 181:872-876

11. Chelmow D, Rodriguez EJ, Sabatini MM (2004) Suture closure of subcutaneous fat and wound disruption after cesarean delivery: a meta-analysis. Obstet Gynecol 103(5 Pt 1):974-980

12. Clark SL, Vines VL, Belfort MA. Fetal injury associated with routine vacuum use during cesarean delivery. Am J Obstet Gynecol. 2008 Apr;198(4):e4. Epub 2008 Mar 4

13. Coutinho IC, Ramos de Amorim MM, Katz L, Bandeira de Ferraz AA. Uterine exteriorization compared with in situ repair at cesarean delivery: a randomized controlled trial. Obstet Gynecol. 2008 Mar;111(3):639-47. Erratum in: Obstet Gynecol. 2008 Jul;112(1):188

14. Cromi A, Ghezzi F, Di Naro E, Siesto G, Loverro G, Bolis P. Blunt expansion of the low transverse uterine incision at cesarean delivery: a randomized comparison of 2 techniques. Am J Obstet Gynecol. 2008 Sep;199(3):292.e1-6

15. Darj E, Nordström ML (1999) The Misgav Ladach method for cesarean section compared to the Pfannenstiel method. Acta Obstet Scand 78:37-41

16. Dodd JM, Anderson ER, Gates S. Surgical techniques involving the uterus at the time of cesarean section. Cochrane Database Syst Rev. 2008; CD004662

17. Durnwald C, Mercer B (2003) Uterine rupture, perioperative and perinatal morbidity after single-layer and double-layer closure at cesarean delivery. Am J Obstet Gynecol 189(4): 925-929

18. Edmiston CE Jr, Seabrook GR, Johnson CP, Paulson DS, Beausoleil CM (2007) Comparative of a new and innovative 2\% chlorhexidine gluconate-impregnated cloth with $4 \%$ chlorhexidine gluconate as topical antiseptic for preparation of the skin prior to surgery. Am J Infect Control 35:89

19. Franchi M, Ghezzi F, Balestreri D, Miglierina M, Triacca P, Cromi A, et al. Nuove tecnologie nel taglio cesareo: il taglio cesareo secondo Stark. $1{ }^{\circ}$ Congresso Congiunto di Medicina Perinatale. Pavia 10-11 Novembre 2000

20. Franchi M, Ghezzi F, Benedetti-Panici PL, Melpignano M, Fallo L, Tateo $\mathrm{S}$ et al (2001) A multicenter collaborative study on the use of cold scalpel and electrocautery for midline abdominal incision. Am J Surg 181:128-132

21. Giacalone PL, Daures JP, Vignal J, Herisson C, Hedon B, Laffargue F (2002) Pfannenstiel versus Maylard incision for cesarean delivery: a randomized controlled trial. Obstet Gynecol 99:745-750

22. Grantcharov TP, Rosenberg J (2001) Vertical compared with transverse incisions in abdominal surgery. Eur J Surg 167: 260-267

23. Harrigill KM, Miller HS, Haynes DE (2003) The effect of intraabdominal irrigation at cesarean delivery on maternal morbidity: a randomized trial. Obstet Gynecol 101(1):80-85

24. Hebammen kämpfen gegen Kaiserschnitte. 2008. http://atemraniosacral.ch/ html/ Tagesanzeiger Kaiserschnitt.pdf

25. Hofmeyr GJ, Mathai M, Shah A, Novikova N. Techniques for cesarean section. Cochrane Databases sys Rev. 2007(1): CD004453.

26. Hohlagschwandtner M, Ruecklinger E, Husslein P, Joura EA (2001) Is the formation of a bladder flap at cesarean necessary? A randomized trial. Obstet Gynecol 98:1089

27. Hopkins L, Smaill F. Antibiotic prophylaxis regimens and drugs for cesarean section. Cochrane Database of Systematic Review 2008, CD 004662

28. Kennare R, Tucker G, Heard A, Chan A (2007) Risks of adverse outcomes in the next birth after a first cesarean delivery. Obstet Gynecol 109(5):1207

29. Kinsella SM (2003) Lateral tilt for pregnant women: why 15 degrees? Anaesthesia 58(9):835-836

30. Luijendijk RW, Jeekel J, Storm KR, Schutte PJ, Hop WC, Drogendijk AC et al (1997) The low transverse Pfannenstiel incision and the prevalence of incisional hernia and nerve entrapment. Ann Surg 225:365-369

31. Magann E, Chauhan S, Bufkin L, Field K, Roberts W, Martin J (2002) Intra-operative haemorrhage by blunt versus sharp expansion of the uterine incision at cesarean delivery: a randomized clinical trail. BJOG 109:448

32. Magann EF, Dodson MK, Ray MA, Harris RL, Martin JN Jr, Morrison JC (1993) Preoperative skin preparation and intraoperative pelvic irrigation: impact on post cesarean endometritis and wound infection. Obstet Gynecol 81:922-925

33. Malvasi A, Tinelli A, Farine D, Rahimi S, Cavallotti C, Vergara D, et al. Effects of visceral peritoneal closure on scar formation at cesarean delivery. Int J Gynaecol Obstet. 2009 Feb 19

34. Mathai M, Hofmeyr GJ. Abdominal surgical incisions for cesarean section. Cochrane Databases Sys Rev. 2007(1): CD004453

35. Morales M, Ceysens G, Jastrow N, Viardot C, Faron G, Vial Y et al (2004) Spontaneous delivery or manual removal of the placenta during caesarean section: a randomised controlled trial. BJOG 111(9):908-912

36. Mowat J, Bonnar J (1971) Abdominal wound dehiscence after caesarean section. Br Med J 2:256-257

37. Murray SF (2000) Relation between private health insurance and high rates of caesarean section in Chile: qualitative and quantitative study. BMJ 321(7275):1501-1505

38. Nabhan AF. Long-term outcomes of two different surgical techniques for cesarean. Int J Gynaecol Obstet. 2008 Jan;100(1):69-75. Epub 2007 Oct

39. Nafisi S. Influence of uterine exteriorization versus in situ repair on post-Cesarean maternal pain: a randomized trial. Int J Obstet Anesth. 2007 Apr;16(2):135-8. Epub 2007 Feb 5

40. Patterson LS, O'Connell CM, Baskett TF (2002) Maternal and perinatal morbidity associated with classic and inverted $\mathrm{T}$ cesarean incisions. Obstet Gynecol 100:633-637

41. Rodriguez AI, Porter KB, O’Brien WF (1994) Blunt versus sharp expansion of the uterine incision in low-segment transverse cesarean section. Am J Obstet Gynecol 171:1022

42. Rubin R. "Answers prove elusive as C-section rate rises". usatoday.com. http://www.usatoday.com/news/health/2008-01-07csections_N.htm. Retrieved on December 30, 2008 
43. Smaill F, Hofmeyr GJ. Antibiotic prophylaxis for cesarean section. Cochrane Database of Systematic Review 2008, CD 004662

44. Stark M (1992) Adhesion-free cesarean section. World J Surg $17: 419$

45. Strauss A. Eröffnung und Verschluss der Bauchwand-Entspricht unsere Routine noch der aktuellen Evidenz?. Speculum-Zeitschrift fuer Gyn. und Geburtshilfe 2009; 27 (1) 6-14

46. Veiga DF, Damasceno CA, Veiga-Filho J, Figueiras RG, Vieira RB, Garcia ES (2009) Randomized controlled trial of the effectiveness of chlorhexidine showers before elective plastic surgical procedures. Infect Control Hosp Epidemiol 30(1):77-79

47. Wallin G, Fall O (1999) Modified Joel-Cohen technique for cesarean delivery. Br J Obstet Gynaecol 106:221-226
48. Webster J, Alghamdi AA. Use of plastic adhesive drapes during surgery for preventing surgical site infection. Cochrane Database Review 2007, CD 006353

49. Wilkinson C, Enkin MW. Absorbable staples for uterine incision at caesarean section. The Cochrane database of systemic reviews 2005

50. Wilkinson C, Enkin MW. Lateral tilt for caesarean section. Cochrane Database Syst Rev. 2006;(3):CD000120.

51. Wilkinson C, Enkin MW. Manual removal of placenta at caesarean section. Cochrane Database Syst Rev. 2006;(3): CD000130

52. Wood RM, Simon H, Oz AU (1999) Pelosi-type vs. traditional cesarean delivery. A prospective comparison. J Reprod Med $44: 788-795$ 